\title{
O CASO TINGA: ANÁLISE DE (MAIS) UM EPISÓDIO DE RACISMO NO FUTEBOL SUL-AMERICANO
}

\author{
Riqueldi Straub Lise \\ Universidade Federal do Paraná, Paraná, Curitiba, Brasil \\ Maria Thereza Oliveira Souza \\ Universidade Federal do Paraná, Paraná, Curitiba, Brasil \\ Larissa Jensen \\ Universidade Federal do Paraná, Paraná, Curitiba, Brasil \\ André Mendes Capraro \\ Universidade Federal do Paraná, Paraná, Curitiba, Brasil
}

\begin{abstract}
Resumo
O objetivo deste estudo consiste em analisar os discursos referentes ao caso de racismo ocorrido na partida de futebol entre a Asociación Civil Real Atlético Garcilaso (Peru) e Cruzeiro Esporte Clube (Brasil), que vitimou Paulo Cesar Tinga, atleta do clube brasileiro. Para tanto foi necessário um levantamento de fontes, encontradas em sites de periódicos esportivos disponíveis na internet, cujas análises foram pautadas nos preceitos teóricos da Análise do Discurso. Notou-se a partir do cruzamento de tais discursos que as penas aplicadas aos infratores são demasiadas brandas, possibilitando a recorrência desse tipo de conduta no campo futebolístico.
\end{abstract}

Palavras-chave: Racismo. Discriminação. Futebol.

\section{Introdução}

No dia 12 de fevereiro de 2014, em partida disputada pela Copa Bridgestone Libertadores, entre Cruzeiro Esporte Clube e o clube peruano Asociación Civil Real Atlético Garcilaso, na cidade de HuanCayo, no Peru, houve a ocorrência de um caso de racismo no futebol. Na disputa, ao adentrar o campo, aos 20 minutos do segundo tempo, o atleta Paulo César Tinga sofreu insultos raciais, proferidos pela torcida peruana, os quais consistiam em imitações de guinchos de macacos emitidos a cada vez que o atleta tocava na bola. Apesar da indignação causada por tais insultos, nenhuma atitude foi tomada pela arbitragem, delegado da CONMEBOL ${ }^{1}$, ou polícia presente. A disputa transcorreu assim até o fim do tempo regulamentar.

O objetivo dessa pesquisa consiste em cruzar diversos discursos (do próprio atleta, da Confederación Sudamericana de Fútbol (CONMEBOL), da Fédération Internationale de

${ }^{1}$ A CONMEBOL é a única federação reconhecida e autorizada pela FIFA para dirigir e controlar o futebol na América do Sul. 
Football Association (FIFA), dos presidentes dos respectivos países, entre outros) ${ }^{2}$, problematizando os posicionamentos dos principais envolvidos no caso de racismo acima citado. Os depoimentos e declarações foram coletados em jornais on-line disponíveis no dia do acontecimento, com sentido de descrever minuciosamente o caso e dias após o ocorrido, intentando ilustrar a repercussão e as consequências da referida discriminação racial. A finalidade de tal cruzamento é ampliar a percepção deste problema social, tendo em vista a pluralidade de opiniões, acentuado pela posição institucional e pela condição cultural dos envolvidos, em especial por serem de países distintos. A partir deste estudo de caso específico, parte-se da hipótese de que as punições impostas pelas instituições que administram o futebol pelo mundo, em casos de discriminação racial, são demasiadamente brandas, o que, em certa medida, não coíbe satisfatoriamente manifestações dessa natureza.

Para tanto, pretende-se utilizar de alguns conceitos/categorias a partir dos procedimentos teóricos da análise do discurso preconizados nas obras de Eni Orlandi, em especial, Análise de Discurso: princípios e procedimentos (2009) e A Linguagem e seu Funcionamento: as formas do discurso (1983), na qual a autora entende que o "conceito de discurso é o da linguagem em interação, ou seja, aquele em que se considera a linguagem em relação às suas condições de produção" (ORLANDI, 1983, p. 145).

Albuquerque Jr. (2011), ao discorrer acerca da conceituação do discurso, destaca.

Quando falar aqui em discurso, estarei me referindo a uma peça oratória proferida em público ou escrita como se fosse para ser lida para um dado público. Estarei me referindo a uma fala ou oração feita para dada audiência, podendo ser escrita previamente ou dita de improviso, tendo ficado registrada de alguma forma, seja através da memória daqueles que a ouviram ou presenciaram, seja através de sua versão original, quando por escrito, seja através de sua reprodução, veiculação e repercussão através dos distintos meios de comunicação social: o jornal, a revista, o rádio, a televisão, o cinema, a internet, a fotografia etc. (ALBUQUERQUE JR., 2001, p. 224).

Pautado em Albuquerque Júnior (2011), considerar-se-á, nesta pesquisa, pelo menos duas formas de discursos. O discurso escrito, tendo como base a legislação peruana quando trata de questões relacionadas ao racismo e à discriminação racial. Levar-se-á ainda a regulamentação da FIFA e da CONMEBOL. Além dos discursos orais, proferidos por ocasião de entrevistas ou depoimentos de alguns dos principais agentes envolvidos.

A maioria das fontes jornalísticas utilizadas para este estudo se encontra no formato on-line, ou seja, foram disponibilizadas na internet por meio de sites e páginas eletrônicas. Segundo Tomaél, "De fato, a Internet abriu um leque amplo na tipologia de fontes de informação" (TOMAÉL, 2001, p. 3). As fontes de informação na internet têm como principais características a velocidade e a quantidade de informações acerca de determinado assunto. Por outro lado, muitas vezes essas informações se apresentam incompletas, discordantes e imprecisas.

\footnotetext{
2 Dilma Roussef (presidente do Brasil), Ollanta Humala (presidente do Peru), Joseph Blatter (presidente da FIFA), Caio Rocha (presidente de comissão da Conmebol no Brasil), José Luis Meiszner (secretário-geral da Conmebol).
} 
Portanto, alguns cuidados devem ser tomados ao selecionar fontes disponibilizadas neste formato, tendo em vista não haver, na maioria dos casos, avaliações prévias daquilo que é postado na rede. Assim, pode-se pensar que um dos maiores problemas com as fontes online resida no quesito qualidade da informação. Segundo Tomaél (2008) "A qualidade de uma informação ou fonte de informação está diretamente relacionada ao seu uso, ou seja, ao usuário que dela necessita. Para que uma fonte seja de qualidade, deve atender a propósitos específicos de uma comunidade de usuários, e isso requer avaliação" (TOMAEL, 2008, p. 6). Com sentido de valorizar a qualidade das informações utilizadas neste estudo, optou-se por utilizar fontes de jornais disponíveis on-line, sites oficiais das duas confederações em questão (FIFA e CONMEBOL) além de portais de notícias esportivas disponíveis na rede. Dessa maneira, houve aqui a preocupação em selecionar os sites mais "confiáveis", embora eivados de subjetividades e interesses.

Esta pesquisa se justifica pela incidência constante de casos de preconceito racial $^{3}$ e de racismo ${ }^{4}$, um problema de ordem social, presente também no cenário esportivo. No Brasil, por exemplo, em um passado muito recente, o árbitro Márcio Chagas foi ofendido racialmente por torcedores do Clube Esportivo Bento Gonçalves (RS) em partida disputada pelo campeonato gaúcho (O ESTADO DE SÃO PAULO, 2014). De maneira semelhante, o meio campo Arouca, atleta do Santos Futebol Clube (SP), também foi vítima de ofensas racistas proferidas pela torcida do Mogi Mirim Esporte Clube (SP) em disputa pelo campeonato paulista (O ESTADO DE SÃO PAULO, 2014). Na cidade de Patos de Minas, estado de Minas Gerais, o atleta Assis, lateral do Uberlândia Esporte Clube (MG), também foi ofendido racialmente, segundo algumas testemunhas, com os seguintes termos: "macaco, negro, safado e fedorento" (ALEIXO, 2014). No âmbito internacional também há a recorrência de atos racistas em partidas de futebol. Pode-se aqui citar os casos do atacante italiano da Associazione Calcio Milan Mário Balotelli; do camaronês Samuel Eto`o, então atacante do Fútbol Club Barcelona; ou ainda do brasileiro Daniel Alves também atleta do Barcelona, dentre muitos outros casos de discriminação racial.

Vale aqui ressaltar a sensível diferença entre as conceituações de preconceito racial entendido por Nogueira (2006) como uma pré-disposição desfavorável quanto à aparência ou ascendência de determinado grupo -, discriminação racial, que a partir do conceito de Cashmore (2007) pode ser pensada como a exteriorização do preconceito racial. E por fim o racismo que segundo Lima e Vala (2004) pode ser entendido como um processo de hierarquização dos grupos sociais, determinado a partir de diversas marcas corporais.

Segundo Dominique Maingueneau, na obra Novas Tendências em Análise do Discurso (1989), faz-se necessário descortinar as condições sob as quais determinado texto foi

\footnotetext{
${ }^{3}$ Nogueira (2006) entende preconceito racial como "Uma disposição (ou atitude) desfavorável, culturalmente condicionada, em relação aos membros de uma população, aos quais se têm como estigmatizados, seja devido à aparência, seja devido a toda ou parte da ascendência étnica que lhes atribui ou reconhece" (NOGUEIRA, 2006, p. 292).

${ }^{4}$ Segundo Lima e Vala (2004), "O racismo, por sua vez, diferentemente do preconceito, é muito mais do que uma atitude. O racismo constitui-se num processo de hierarquização, exclusão e discriminação contra um indivíduo ou toda uma categoria social que é definida como diferente com base em alguma marca física externa (real ou imaginada), a qual é re-significada em termos de uma marca cultural interna que define padrões de comportamento." (LIMA; VALA, 2004, p. 402).
} 
produzido. Nesse sentido, o autor define as condições de produção da seguinte maneira: "Através dela, designa-se, geralmente, o 'contexto social' que 'envolve' um corpus, isto é um conjunto desconexo de fatores entre os quais são selecionados previamente os elementos que permitem descrever uma 'conjuntura"” (MAINGUENEAU, 1989, p. 53). Com a intenção de descrever a conjuntura na qual os discursos dos agentes envolvidos neste caso de discriminação racial estão inscritos, segue, nos próximos parágrafos, o contexto (sentido amplo) e a cena (sentido restrito ao momento da produção) que servirão de base para a análise proposta.

\section{Os discursos}

O poder legislativo peruano, assim como o brasileiro, também considera atos de discriminação racial ou racismo crimes passíveis de penas. O artigo 323 da lei número 28. 867 declara:

El que, por sí o mediante terceros, discrimina a uma o más personas o grupo de personas, o incita o promueve em forma pública actos discriminatórios, por motivo racial, religioso, sexual, de factor genético, filiación, edad, discapacidad, idioma, identidad étnica y cultural, indumentaria, opinión política o de cualquier índole, o condición econômica, com el objeto de anular o menoscabar El reconocimiento, goce o ejercicio de los derechos de la persona, será reprimido com pena privativa de liberdad no menor de dos años, ni mayor de tres o com prestación de servicios a la comunidad de sessenta a ciento e veinte jornadas (EL PERUANO, 2006, s/p.).

Embora o racismo e a discriminação racial sejam considerados um grave problema social de abrangência mundial, não são todos os países que classificam tais condutas como crimes passíveis de penas (reclusão) ou multas. Mas as legislações brasileira e peruana se mostram pouco tolerantes com discriminações desta natureza. Sendo assim, pode-se inferir que as leis vigentes em determinados países reflitam as demandas específicas daquela sociedade.

No âmbito esportivo, mais especificamente no futebol, algumas medidas, com o intuito de coibir tal tipo de conduta discriminatória, foram tomadas. A FIFA aprovou em maio de 2013 uma nova resolução. A mesma impõe que advertências, multas ou punições podem ser aplicadas em caso de ofensa racista de ordem leve ou de primeira infração. Para atitudes mais graves ficou estabelecida a possibilidade de perda de pontos, o rebaixamento ou ainda a exclusão de competições (UOL ESPORTE, 2013). A resolução intitulada Resolution on the Fight Against Racism and Discrimination publicada durante o $63^{\circ}$ Congresso da FIFA nas Ilhas Mauricio, determina que:

However, in order to harmonise the pronounced sanctions on a worldwide level, the sanctions imposed on a club or representative team shall in principle be issued in a two-stage approach: 1) For a first or a minor offence, the sanctions of a warning, a fine and/or the playing of a match behind closed doors shall be applied. 2) For reoffenders or for serious incidents, sanctions such as point deductions, expulsion from a competition or relegation should be applied. Furthermore, any person (player, official, 
match official, etc.) who commits such an offence shall be suspended for at least five matches combined with a stadium ban as foreseen in the FDC (FIFA, 2013, p. 03).

A CONMEBOL menciona em seu Regulamento Disciplinar as possíveis punições referentes a condutas discriminatórias, tal como aquela ocorrida na ocasião da disputa entre Cruzeiro e Real Garcilaso. O artigo 12 do Regulamento Disciplinar da CONMEBOL intitulado "Discriminación y comportamientos similares", determina que:

1.Cualquier persona que insulte o atente contra la dignidad humana de otra persona o grupo de personas, por cualquier medio, por motivos de color de piel, raza, etnia, idioma, credo u origen será suspendida por un mínimo de cinco partidos o por un periodo de tiempo específico.

2.Cualquier asociación miembro o club cuyos aficionados incurran en los comportamientos descritos en el apartado anterior será sancionados con una multa de al menos USD 3.000.

3.Si las circunstancias particulares de un caso lo requieren, el órgano disciplinario competente podrá imponer sanciones adicionales a la asociación miembro o al club responsable, como jugar uno o más partidos a puerta cerrada, la prohibición de jugar un partido en un estádio determinado, la concesión de la victoria del encuentro por el resultado que se considere, La deducción de puntos o la descalificación de la competición. [...] (CONMEBOL, 2012, p. 10).

Pode-se perceber, a partir da análise da Resolução sobre a luta contra o racismo e a discriminação, bem como no Regulamento Disciplinar da CONMEBOL, a possibilidade de coibir atos dessa natureza. No entanto, as punições mais contundentes só devem ser aplicadas em caso de reincidência, o que fragiliza o posicionamento das instituições em relação ao combate do racismo e da discriminação racial.

Embora tenha sido evidenciada pela transmissão de TV, os insultos raciais ocorridos durante a partida não foram mencionados na súmula pelo árbitro, o venezuelano José Argote. Dada a intensa repercussão do caso nos meios de comunicação, o brasileiro Caio Rocha, presidente do Tribunal Disciplinar da CONMEBOL, também advogado, foi solicitado a prestar alguns esclarecimentos acerca do ocorrido em entrevista ao site da ESPN:

Não vi a súmula e nem vou participar do julgamento, mas a notificação que chegou da Conmebol foi de que a arbitragem não descreveu o caso de racismo na súmula. Nessa situação, contudo, o próprio vídeo com as imagens pode ser suficiente. Não sei se de repente o juiz não percebeu os gritos durante o jogo (ROCHA, 2014).

O discurso de Rocha demonstra excessiva prudência em esclarecer alguns fatos. Já no início, o mesmo intenta se desonerar de qualquer cobrança vinda dos repórteres ao declarar não ter tido acesso a súmula do jogo, mesmo tendo passado dois dias da ocorrência. Porém, ao afirmar antecipadamente que não participaria do julgamento, tendo em vista que um clube brasileiro estava envolvido, Rocha dá indícios de que a instituição estava ciente da repercussão do caso e já iniciava um procedimento disciplinar com o sentido de apurar a gravidade da situação, mesmo que não houvesse na súmula qualquer referência às 
manifestações racistas provenientes da torcida peruana.

Considerando a posição institucional que ocupa, possivelmente, Rocha tivesse a intenção de minimizar as responsabilidades, ao tentar justificar a ausência do relato do caso de discriminação racial na súmula do jogo, aventando a torpe possibilidade de que o árbitro não tivesse ouvido os apupos da torcida. Tal justificativa parece não proceder, primeiro, porque os auxiliares, ou mesmo o quarto árbitro poderiam ter ouvido as manifestações racistas e nenhuma atitude fora tomada, e segundo, porque os atletas que disputavam a partida estavam ouvindo as agressões discriminatórias.

Vale aqui ressaltar que a passividade atribuída ao árbitro está circunscrita ao fato de o mesmo não ter relatado na súmula as manifestações discriminatórias vindas das arquibancadas. Pois, considerando a Resolução da FIFA sobre a luta contra o racismo e a discriminação, bem como o Regulamento Disciplinar da CONMEBOL, pode-se perceber que não há nenhum dispositivo regulamentar que oriente a arbitragem a suspender a partida ou algo semelhante.

Segundo o site $O$ Estado de São Paulo, Caio César Rocha pronunciou-se novamente acerca do assunto, dessa vez em entrevista concedida à Rádio Itatiaia de Minas Gerais, na qual expressava sua expectativa quanto à intensidade da suposta pena ao clube peruano Real Garcilaso.

Pelo histórico do tribunal, acredito que será analisado o nível de gravidade, mas também com a intenção de aplicar uma pena mais didática, não muito radical, mas alertando o clube e os demais que participam da competição, que se situações como essa voltarem a se repetir, as penas podem ser mais graves (ROCHA, 2014).

A entrevista de Rocha, dois dias antes do resultado do julgamento, aponta para uma pena branda e didática, o que, segundo ele já faz parte de um histórico do Tribunal Disciplinar da CONMEBOL. Tal declaração é conflitante se comparada com a expectativa do advogado especialista em direito desportivo Eduardo Carlezzo, que em entrevista concedida ao site globo.com considera o caso extremamente grave e espera que a pena seja severa, justamente com sentido de coibir outras manifestações desta natureza (CARLEZZO, 2014). A partir da fala dos dois juristas é possível perceber que as expectativas são muito distintas, embora os argumentos estejam pautados em uma mesma lógica, ambos prenunciam uma pena didática e pedagógica.

A partir dos discursos adversos proferidos pelos dois advogados, pode-se pensar nas relações de força que constituem tais discursos. Orlandi (2009), ao tratar das relações de força, discorre: "segundo essa noção, podemos dizer que o lugar a partir do qual fala o sujeito é constitutivo do que ele diz" (ORLANDI, 2009, p. 39). Daí a importância de desvelar as condições de produção de determinados discursos, enquanto Caio Rocha está institucionalmente vinculado ao tribunal disciplinar da CONMEBOL, seu discurso possivelmente concorde com os preceitos da referida organização. No mesmo sentido, o discurso de Eduardo Carlezzo, provavelmente também esteja sujeito a algumas relações de força, considerando que tal jurista é sócio fundador da Carlezzo Advogados, empresa esta que, "(...) já participou de uma ampla gama de atividades e transações na assessoria a atletas, agentes, clubes de futebol, empresas, investidores, federações, entre outros" (CARLEZZO ADVOGADOS, 2001). Dessa maneira é possível perceber que os discursos de ambos os 
advogados não são neutros, ao contrário, são precedidos por interesses das instituições as quais estão vinculados.

$\mathrm{Na}$ tentativa de avançar em uma reflexão acerca da coerção das instituições sobre os discursos de alguns agentes vinculados a elas, torna-se imprescindível analisar o discurso de Joseph Blatter, presidente da FIFA, considerada a principal instituição regulamentadora do futebol no mundo. Em entrevista concedida ao jornal britânico The Guardian, o dirigente afirma que:

Jogos com portões fechados estão inclusos também no código da Fifa, mas eu acho que essa penalidade é indevidamente excessiva como um instrumento muito duvidoso. Eles representam uma punição coletiva desproporcional. Além disso, ela acaba excluindo torcedores inocentes. Jogos assim prejudicam o próprio futebol. Os causadores do problema que precisam ser punidos. Está claro para mim que os clubes são responsáveis pelos hooligans. Na minha mente, só existe uma saída: sanções esportivas são efetivas. Tem que fazer os clubes se machucarem de verdade. Caso contrário nada vai mudar (BLATTER, 2014).

O discurso de Blatter é vago, pois não apresenta uma proposta efetiva quanto ao tipo e nem quanto à intensidade das punições referentes à conduta de discriminação racial. $\mathrm{O}$ presidente da FIFA considera que jogos com portões fechados é desproporcional e despersonalizado. Segundo ele, os clubes devem ser punidos, pois são os responsáveis por tais manifestações. No entanto o dirigente não especifica de que maneira se pode "machucar um clube de verdade".

A nova resolução disciplinar da FIFA prevê punições, porém, estas só podem ser aplicadas em caso de reincidência do clube, pois ao primeiro ato racista, recebe apenas uma pena leve ou advertência formal. Conforme a proposição de Blatter, a pena com portões fechados é desproporcional. Sendo assim, as punições de perda de pontos na tabela de classificação, possibilidade de rebaixamento ou mesmo a exclusão de um clube de determinado campeonato parecem estar definitivamente fora de questão. Assim, pode-se pensar que a única punição possível, segundo Blatter, consista em aplicar multas, embora o dirigente não tenha deixado evidente este posicionamento em seu discurso.

Novamente é possível notar as relações de força (ORLANDI, 2009) presentes no discurso de Blatter. As preocupações do dirigente estão centradas principalmente no receio de que algumas punições possam prejudicar o aspecto esportivo do futebol em detrimento das questões humanitárias ensejadas por casos de discriminação racial. Em outras palavras os interesses da FIFA no bom andamento do futebol tendem a sobrepujar valores como equidade racial e dignidade humana.

Tão perigoso quanto o posicionamento de Blatter, é o discurso protagonizado pelo secretário-geral da CONMEBOL, o argentino José Luis Meiszner, ao se referir aos atos racistas protagonizados pela torcida da equipe peruana:

Um moreno peruano imitando macaco para um brasileiro um pouco mais escuro que ele não é uma discriminação racial. É sim uma provocação maleducada [...] O que se vê na América do Sul é algo que, na maioria dos casos, não deve ser considerado racismo [...] Nós, os sul-americanos, não somos racistas. Somos sim, o povo mais mal-educado do mundo. Nos falta 
até mesmo cultura para, filosoficamente falando, provocarmos discriminação racial (MEISZNER, 2014).

O polêmico discurso de Meiszner não considera como atos de discriminação racial os insultos proferidos pela torcida do clube peruano. $\mathrm{O}$ dirigente entende que a hostilidade foi apenas uma provocação mal educada propiciada por uma incapacidade cultural dos sulamericanos. Este discurso paradoxal é no mínimo inconsequente, pois, conceber que determinada população não detém as condições culturais necessárias para cometer discriminação, pode legitimar tal prática. Na contramão da maioria das nações e de algumas instituições que tentam criminalizar o racismo com sentido de diminuir as desigualdades sociorraciais, Meiszner, secretário geral da CONMEBOL, tenta amenizar retoricamente essas ocorrências.

De maneira semelhante, o próprio presidente da CONMEBOL, o uruguaio Eugênio Figueredo, tenta contemporizar ofensas racistas, afirmando que:

Discriminação é um tema mundial. Não é de uma partida. É um sistema de vida. A discriminação não se dá apenas no futebol. O mundo inteiro é contra discriminação. Ninguém fica alegre com isso. $O$ ser humano tem que progredir um pouquinho e aprender a conviver e aceitar as diferenças (FIGUEREDO, 2014).

A declaração de Figueredo se deu após a intensa repercussão do discurso de Meiszner na imprensa internacional, além de uma vigorosa cobrança de instituições que lutam pelo fim das discriminações raciais no mundo, as quais cobravam da CONMEBOL uma posição mais contundente contra o racismo. $\mathrm{O}$ dirigente fala de forma evasiva e fatalista, e tenta naturalizar eventos deste tipo. Possivelmente por estes dois motivos elencados por Figueredo, diversas nações tenham reunido esforços no sentido de criminalizar tais práticas. Concorda-se com o dirigente quando este afirma que a discriminação não se dá apenas no futebol, no entanto cabe aqui um questionamento: o que o futebol tem feito para que este tipo de situação não aconteça mais?

Em contrapartida aos depoimentos de Meiszner e Figueredo, o presidente do Peru, Ollanta Humala Tasso por meio de uma rede social deu a seguinte declaração:

Um país tão diverso como o nosso e que fortalece sua identidade, com todas suas culturas, não deve admitir reações racistas de nenhum tipo. Expressões como as de ontem em uma partida de futebol devem originar indignação e impulsionar nossa luta contra todo tipo de discriminação (TASSO, 2014).

Na declaração de Tasso fica evidenciado um pensamento contrário ao dos dirigentes da CONMEBOL. O principal mandatário peruano mostrou-se muito mais preocupado com os aspectos sociorraciais e humanitários em detrimento dos interesses da organização futebolística. Amparado pela legislação daquele país, o presidente do Peru concebe tal ocorrência como uma oportunidade de combate efetivo contra este tipo de situação. $\mathrm{O}$ que indica que os pensamentos de Meiszner e Figueredo não são predominantes, embora reflitam o posicionamento da instituição a qual estão vinculados. De forma análoga, a presidente brasileira Dilma Rousseff, se posicionou da seguinte maneira. 
Foi lamentável o episódio de racismo contra o jogador Tinga, do Cruzeiro, no jogo de ontem, no Peru. Ao sair do jogo, Tinga disse que trocaria seus títulos por um mundo com igualdade entre as raças. Por isso, hoje o Brasil inteiro está fechado com o Tinga. Acertei com a ONU e com a Fifa que a nossa Copa das Copas também será a Copa contra o racismo. Porque o esporte não deve ser jamais palco para o preconceito (ROUSSEF, 2014).

O discurso da presidente brasileira também enfatiza um posicionamento em favor dos aspectos humanitários contra o racismo, como prevê a legislação brasileira. Roussef demonstra ainda uma preocupação em utilizar a Copa do Mundo como um instrumento contrário às condutas racistas. Tal preocupação realmente permeou a realização do Campeonato Mundial realizado no Brasil. Discursos proferidos pelos capitães das seleções antes do início das partidas ou ainda faixas com os dizeres "Não ao racismo" não foram inéditas - considerando que essas atitudes já haviam sido tomadas pela FIFA na edição anterior em 2010, na África do Sul - mas demonstravam certa preocupação com incidentes desta natureza no principal evento de futebol do mundo.

Após 39 dias da manifestação discriminatória, A CONMEBOL anunciou a punição da Real Garcilaso: multa de US\$ 12 mil, cerca de R \$ 28 mil, referente à pena pelos insultos proferidos à Tinga por alguns integrantes da torcida peruana (CONMEBOL, 2014). Vale aqui ressaltar que os valores aplicados sob a forma de multa são irrisórios em se tratando de clubes de futebol que disputam um torneio de porte intercontinental. Para se ter ideia da desproporção da multa aplicada ao clube peruano basta saber que o elenco do clube estava avaliado na época do episódio em cerca de dois milhões de reais. Portanto, pode-se aqui questionar os efeitos que essa penalização teria em termos didáticos, pedagógicos e até preventivos.

Logo após o término do jogo, o atleta Tinga, alvo dos insultos, pronunciou-se da seguinte maneira:

Eu queria não ganhar todos os títulos da minha carreira e ganhar o título contra o preconceito contra esses atos racistas. Trocaria por um mundo com igualdade entre todas as raças e classes. [...] A gente tenta esquecer, competir em campo. Fico chateado com isso em pleno 2014, um país tão próximo da gente, mas infelizmente aconteceu. Já joguei longe, joguei vários anos na Alemanha e nunca vi isso na minha vida (TINGA, 2014).

Pelo depoimento do atleta, fica claro que esse tipo de acontecimento afeta profundamente a pessoa atingida pela infâmia discriminatória e, dessa maneira, a punição aplicada pela entidade que deveria coibir esse tipo de ofensa torna-se ainda menos significativa, já que nem sequer houve a tentativa de identificação dos responsáveis, tornando a probabilidade de reincidência alarmante.

\section{Considerações finais}

Foi possível perceber ao longo deste estudo que os discursos dos regulamentos das principais organizações que regulam a prática do futebol no mundo e na América do Sul (FIFA e CONMEBOL) são providos de dispositivos que efetivamente poderiam conter atitudes de caráter racista. No entanto, os próprios dirigentes das referidas instituições são 
contrários à aplicação de penalidades mais contundentes. A aplicação de penas irrisórias por parte das organizações esportivas contraria a lógica da luta por uma sociedade igualitária e sem preconceitos não só raciais, mas de qualquer tipo.

Vale aqui ressaltar que os mandatários das nações dos clubes envolvidos no incidente de discriminação racial, bem como parte de suas populações consideram atos dessa natureza como um grave problema social a ser combatido. As próprias legislações dos dois países Peru e Brasil - consideram crime atos de racismo e injúria racial $^{5}$, prevendo inclusive reclusão de um a três anos. Ao problematizar o posicionamento de alguns dos principais envolvidos, percebeu-se uma série de contradições ocasionadas principalmente pelo envolvimento institucional de alguns agentes, em especial dos principais dirigentes do futebol mundial e sul-americano, tornando tais organizações coniventes com o problema racial.

Assim, a hipótese lançada no início deste estudo - de que as punições impostas pelas instituições que administram o futebol pelo mundo, em casos de discriminação racial, são demasiadamente brandas - torna-se plausível, considerando a recorrência de atos racistas e de discriminação racial em partidas de futebol.

Se por um lado, as instituições de caráter humanitário e as nações, na figura de seus presidentes, estão preocupadas com os impactos sociais provocados por tais eventos, por outro as organizações que regem o futebol parecem estar centradas nos problemas que as sanções punitivas podem causar para o espetáculo.

Antes da finalização deste estudo, outro caso de discriminação racial repercutiu de forma intensa nos meios de comunicação brasileiros. Em partida realizada pela Copa do Brasil entre o Grêmio Foot-Ball Porto Alegrense e o Santos Futebol Clube, no final de agosto do corrente ano, em Porto Alegre, o goleiro "Aranha" da equipe santista foi vítima de discriminação racial por parte de alguns membros da torcida do clube gaúcho, chamando-o de "macaco". Pode-se perceber uma grande mobilização da imprensa e da população brasileira, nas redes sociais, cobrando punições aos infratores.

Desta feita, as penalidades foram mais severas, o clube gaúcho foi excluído da competição e os agressores foram indiciados e responderão por crime de racismo e injúria racial. Tal punição parece descortinar uma nova fase no combate ao racismo no campo futebolístico.

\title{
THE CASE TINGA: ONE MORE EPISODE OF RACISM IN SOUTH AMERICAN SOCCER
}

\begin{abstract}
This artice aims to analyze the discourses about the case of racism against the Brazilian player Paulo Cesar Tinga, which occurred during the soccer match between Asociación Civil Real Atlético Garcilaso (Peru) and Cruzeiro Esporte Clube (Brazil). For this, it was used the theoretical precepts of Discourse Analysis to understand the sources found in sporting periodicals available on the Internet sites. It was possible to infer that the punishment for offenders are too lenient, which turns this type of conduct an ordinary act in the soccer field.
\end{abstract}

Key words: Racism. Discrimination. Soccer. ${ }^{5}$ Vale aqui destacar a existência de um debate jurídico, no qual há discordâncias quanto ao enquadramento de
casos de racismo e injúria racial. 


\section{EL CASO TINGA: ANÁLISIS DE (MÁS) UN EPISODIO DE RACISMO EN EL FÚTBOL SUR-AMERICANO}

\section{Resumen}

El objetivo de este estudio es analizar los discursos sobre el caso de racismo ocurridos en el partido de fútbol entre la Asociación Civil Real Atlético Garcilaso (Perú) y Cruzeiro Esporte Clube (Brasil), que victimó Paulo César Tinga, atleta del club brasileño. Para ello necesitábamos una encuesta de las fuentes que se encuentran en los periódicos deportivos disponibles en los sitios de Internet, cuyos análisis fueron guiados en preceptos teóricos de Análisis del Discurso. Se tomó nota de la intersección de estos discursos que las sanciones para los infractores son demasiado leves lo que permite que sea recurrente este tipo de conducta es recurrente en el campo de fútbol.

Palabras claves: Racismo. Discriminación. Fútbol.

\section{Referências}

ALBUQUERQUE JR., D. M. Discursos e pronunciamentos: a dimensão retórica da historiografia. In: PINSKY, C. B.; LUCA, T. R. (Org.). O historiador e suas fontes. São Paulo: Contexto, 2011, p. 223-249.

ALEIXO, C. Lateral do Uberlândia sofre ofensas racistas; torcedor do Mamoré é detido. 10 mar. 2014. Disponível em: <http://globoesporte.globo.com/mg/triangulomineiro/noticia/2014/03/torcedor-do-mamore-e-preso-por-ofensas-racistas-jogador-douec.html>. Acesso em: 06 ago. 2014.

BLATTER, J. Blatter diz que casos de racismo não devem ser punidos com portões fechados. 17 abr. 2014. Disponível em: <http://esporte.uol.com.br/futebol/ultimasnoticias/2014/04/17/blatter-diz-que-casos-de-racismo-nao-devem-ser-punidos-com-portoesfechados.htm.>. Acesso em: 10 ago. 2014.

BRASIL. Lei $\mathrm{n}^{\circ}$ 7.716, de 05 de janeiro de 1989. Define os crimes resultantes de preconceito de raça ou de cor. Diário Oficial da República Federativa do Brasil, Brasília, DF, 05 jan. 1989.

CASHMORE, E. Dicionário de relações étnicas e raciais. São Paulo: Summus, 2000.

CARLEZZO ADVOGADOS. Eduardo Carlezzo, sócio fundador. 2011. Disponível em: <http://www.carlezzo.com.br/pt/ver-equipe.php?id=3>. Acesso em: 01 set. 2014.

CARLEZZO, E. Árbitro venezuelano não relata ofensas racistas a Tinga em súmula. 14 fev. $2014 . \quad$ Disponível em: <http://globoesporte.globo.com/futebol/times/cruzeiro/noticia/2014/02/arbitro-venezuelanonao-relatou-ofensas-racistas-tinga-em-sumula.html>. Acesso em: 07 ago. 2014.

CONMEBOL. Reglamento disciplinário. Gran Asunción: 2012.

Tribunal de disciplina sanciona Real Garcilaso. 24 mar. 2014. Disponível em: <http://www.conmebol.com/pt-br/content/tribunal-de-disciplina-sanciona-real-garcilaso>. 
Acesso em: 12 ago. 2014.

EL PERUANO. Ley n ${ }^{\circ} 28.867$, de 09 de agosto de 2006. Ley que modifica el artículo 323 del código penal. Normas legales, 09 ago. 2006.

FIFA. Resolution on the fight against racism and discrimination. $63^{\circ}$ Congress. Mauritius: 30 maio 2013.

FIGUEREDO, E. Presidente da Conmebol condena racismo, mas não diz se clube será punido. 18 fev. 2014. Disponível em: <http://oglobo.globo.com/esportes/presidente-daconmebol-condena-racismo-mas-nao-diz-se-clube-peruano-sera-punido-11637314>. Acesso em: 31 jul. 2014.

IBGE. Pesquisa Nacional por Amostra de Domicílio, v. 32, 2012.

LIMA, M. E. O.; VALA, J. As novas formas de expressão do preconceito e do racismo. Estudos psicológicos, Natal, v. 9, n. 3, p 401-411, 2004.

MAINGUENEAU, D. Novas tendências em análise do discurso. Campinas: Pontes, 1989.

MEISZNER, J. L. Para número 2 da Conmebol, Tinga não sofreu racismo. 21 mar. 2014. Disponível em: <http://www1.folha.uol.com.br/esporte/2014/03/1428725-para-numero-2-daconmebol-tinga-nao-sofreu-racismo.shtml>. Acesso em: 15 ago. 2014.

NOGUEIRA, O. Preconceito racial de marca e preconceito racial de origem: sugestão de um quadro de referência para a interpretação do material sobre relações raciais no Brasil. Tempo Social, São Paulo, v. 19, n. 1, p. 287-308, jun., 2007.

O ESTADO DE SÃO PAULO. Conmebol deve decidir caso de racismo contra Tinga na segunda feira. 21 mar. 2014. Disponível em: $<$ http://esportes.estadao.com.br/noticias/futebol,conmebol-deve-decidir-caso-de-racismocontra-tinga-na-segunda-feira,1143257>. Acesso em: 06 ago. 2014.

ORLANDI, E. P. A Linguagem e seu funcionamento: as formas do discurso. São Paulo: Brasiliense, 1983.

Análise de Discurso: princípios e procedimentos. Campinas: Pontes, 2009.

ROCHA, C. C. Árbitro venezuelano não relata ofensas racistas a Tinga em súmula. 14 fev. $2014 . \quad$ Disponível em: <http://globoesporte.globo.com/futebol/times/cruzeiro/noticia/2014/02/arbitro-venezuelanonao-relatou-ofensas-racistas-tinga-em-sumula.html>. Acesso em: 07 ago. 2014.

Conmebol deve decidir caso de racismo contra Tinga na segunda feira. 21 mar. 2014. Disponível em: <http://esportes.estadao.com.br/noticias/futebol,conmebol-deve-decidircaso-de-racismo-contra-tinga-na-segunda-feira,1143257>. Acesso em: 06 ago. 2014. 
ROUSSEF, D. Twiter. 13 fev. 2014. Disponível em: <https://twitter.com/dilmabr/status/433922695953403904>. Acesso em: 25 ago. 2014.

TASSO, O. H. Presidente do Peru condena racismo contra Tinga: "Não devemos admitir". 13 fev. 2014.2 Disponível em: <http://globoesporte.globo.com/futebol/times/cruzeiro/noticia/2014/02/presidente-do-perucondena-racismo-contra-tinga-nao-devemos-admitir.html>. Acesso em: 31 jul. 2014.

TINGA, P. C. Vítima de racismo, Tinga trocaria glórias por "título contra o preconceito". 132 fev. $2014 . \quad$ Disponível em: $<$ http://m.globoesporte.globo.com/futebol/times/cruzeiro/noticia/2014/02/vitima-de-racismono-peru-tinga-diz-que-trocaria-titulos-por-igualdade.html>. Acesso em: 28 ago. 2014.

TOMAÉL, M. I.; ALCARÁ, A. R.; SILVA, T. E. Fontes de informação na internet: critérios de qualidade. In: TOMAÉL, M. I. (Org.). Fontes de informação na internet. Londrina: Eduel, 2008, p. 03-28.

TOMAÉL, M. I. et. al. Avaliação de fontes de informação na internet: critérios de qualidade. Informação \& Sociedade: Estudos. João Pessoa: vol. 11, n. 2, 2001. p. 01-14.

UOL ESPORTE. Resolução da FIFA propõe medidas mais duras contra o racismo. 28 mai. 2013. Disponível em: <http://esporte.uol.com.br/ultimasnoticias/afp/2013/05/28/resolucao-da-fifa-propoe-medidas-mais-duras-contra-oracismo.htm>. Acesso em: 31 jul. 2014.

UOL ESPORTE FUTEBOL. Biografias. 2014. Disponível em: <http://esporte.uol.com.br/futebol/biografias/199/tinga/>. Acesso em: 05 ago. 2014.

Recebido em: 02/10/2014

Revisado em: 03/05/2015

Aprovado em: 06/08/2015

Endereço para correspondência:

ricklise@ig.com.br

Riqueldi Straub Lise

Universidade Federal do Paraná, Departamento de Educação Física.

Rua Coração de Maria, 92 - BR 116 km 95

Campo Comprido

80215-370 - Curitiba, PR - Brasil 